\title{
Correction to: Rapid and controllable perforation of carbon nanotubes by microwave radiation
}

\author{
Neda Ojaghi ${ }^{1} \cdot$ Maryam Mokhtarifar $^{1} \cdot$ Zahra Sabaghian $^{1} \cdot$ Hamed Arab $^{1} \cdot$ Morteza Maghrebi $^{1} \cdot$ Majid Baniadam $^{1}$
}

Published online: 14 May 2018

○) Springer-Verlag GmbH Germany, part of Springer Nature 2018

Correction to: Applied Physics A (2018) 124:367

$$
\text { https://doi.org/10.1007/s00339-018-1787-y }
$$

In the original publication the wrong e-mail address for the corresponding author was given.

The correct address for the corresponding author Morteza Maghrebi must read mmaghrebi@um.ac.ir.

The original article can be found online at https://doi.org/10.1007/ s00339-018-1787-y.

Morteza Maghrebi

mmaghrebi@um.ac.ir

1 Department of Chemical Engineering, Faculty

of Engineering, Ferdowsi University of Mashhad, Mashhad,

Iran 